\title{
Improved Performance of Silicon Rubber Insulation with Coal Fly Ash Micro Filler
}

\author{
Tajuddin Waris ${ }^{\mathrm{a}, *}$, Yoshinobu Murakami ${ }^{\mathrm{b}}$, Naohiro Hozumi ${ }^{\mathrm{c}}$, Tomohiro Kawashima ${ }^{\mathrm{d}}$, Salama Manjang ${ }^{\mathrm{e}}$, Ikhlas \\ $\mathrm{Kitta}^{\mathrm{f}}$ \\ aDepartment of Electrical and Electronic Information, Toyohashi University of Technology. Email: t17922@edu.tut.ac.jp \\ bepartment of Electrical and Electronic Information, Toyohashi University of Technology. Email: murakami@ee.tut.ac.jp \\ 'Department of Electrical and Electronic Information, Toyohashi University of Technology. Email: hozumi@ee.tut.ac.jp \\ ${ }^{\mathrm{d} D e p a r t m e n t ~ o f ~ E l e c t r i c a l ~ a n d ~ E l e c t r o n i c ~ I n f o r m a t i o n, ~ T o y o h a s h i ~ U n i v e r s i t y ~ o f ~ T e c h n o l o g y . ~ E m a i l: ~ k a w a s h i m a @ e e . t u t . a c . j p ~}$ \\ eDepartment of Electrical Engineering, Hasanuddin University. Email: salamamanjang@unhas.ac.id \\ fDepartment of Electrical Engineering, Hasanuddin University. Email: ikhlaskitta@gmail.com
}

\begin{abstract}
This paper presents the effect of coal fly ash micro filler (CFA) on the electrical properties of silicon rubber insulation. The observed electrical properties are volume resistance, surface resistance, flash over inception voltage dependence on CFA filler loading and temperature. The type of silicon used is room temperature vulcanized (RTV) 683 and the filler concentrations of the matrix are 0,10.20,30,40 per-hundred gram of resin (phr). The test results show that the surface resistance increased significantly with the increasing of CFA loading filler. The increasing of volume resistance is nonlinear; the volume resistance tends to decrease when the CFA loading filler exceeds 20 phr. Flashover inception voltage increase with the increasing of CFA filler loading, but decrease with the temperature increase.
\end{abstract}

Keywords: coal fly ash; flashover; resistance; silicon rubber

\section{Introduction}

Today, polymeric insulators probably the most efficient solution for outdoor insulator due to some advantages such as ultralow conductivity, excellent hydrophobicity, high flashover voltage, easy maintenance, and processing at low cost. The polymeric insulators are incredibly suitable for applications in the transmission and distribution sector. It has an impressive spectrum of electrical, physical, mechanical and chemical properties [1].

Compared to other polymeric materials, silicones exhibit very good long lasting hydrophobicity. Insulating components made of silicone rubber compounds still repel water after many years in application. Silicone elastomers are particularly resistant to UV radiation, even harsh weather conditions, as found in coastal regions. In addition, Silicones have high electrical resistivity, low dielectric loss factor, extremely elastic, low flammability and temperature stability [2-3].

The polymer can not perform satisfactorily in numerous application in pure form (unfilled). Therefore, the application of filler on polymer insulation is required to

${ }^{*}$ Corresponding author. Tel.: +81-80-2290-8979

Machi Hata Cho- Aza Morita 49, Sakou Jutaku 1-17

Toyuhashi Shi, Japan, 441-8101 improve mechanical and electrical properties and to reduce unit the cost of insulation. Currently, the popular filler used are $\mathrm{SiO}_{2}, \mathrm{Al}_{2} \mathrm{O}_{3}$ and $\mathrm{MgO}$ in nano and micro size [3-5].

They have been reported as good filler from the viewpoint of electrical properties. However, their price is still very high hence the unit price of insulation increase.

CFA is the waste by-product from coal steam power. Its vast majority of chemical content are $\mathrm{SiO}_{2}, \mathrm{Al}_{2} \mathrm{O}_{3}$, and $\mathrm{Fe}_{2} \mathrm{O}_{3}$. Also, its price is very cheap even almost free and available abundantly. Those reasons make coal fly ash could be applied as a filler on silicon rubber insulation [6].

Up to now, the application of coal fly ash as a filler mostly on material construction and ceramic industry [7].

\section{Material and Experimental Method}

\subsection{Silicon rubber}

Silicone or Polysiloxanes rubber is an elastomer compose of silicon, carbon, hydrogen, and oxygen. It is widely applied as material insulation on electrical power system particularly in a high voltage transmission line to substitute porcelain insulation. Silicon rubber has superiority properties over porcelain insulator. The most outstanding property of silicone rubber is excellent dielectric 
properties, low relative permittivity, low dielectric loss, high stretch ability and excellent hydrophobicity.

Silicone rubber offers excellent resistance to extreme temperatures, being able to apply from -100 to $300{ }^{\circ} \mathrm{C}$. Some other properties such as elongation, creep, cyclic, flexing, tear strength, thermal conductivity, high compression, fire resistance and high tensile. Therefore, it is suitable for the application at high polluted and when retention of initial shape and mechanical strength are requirements under heavy thermal stress or sub-zero temperatures. In addition, it has a carbon-to-carbon backbone which can leave it susceptible ozone, heat and other aging factors that silicone rubber can withstand well. By which silicone rubber one of the elastomers of choice in extreme environment application [8].

Silicon differs from other polymers. Its backbones consist of cycling $\mathrm{Si}-\mathrm{O}-\mathrm{Si}$ units. Unlike many other polymers that contain carbon backbones. Silicon has a very large angle and bond length compared to other polymers such as polyethylene. Hence, It can move farther and change formation easily yielding a flexible material. In addition, it also tends to be chemically inert, due to the strength of the silicon-oxygen bond [9].

There some kinds of silicon rubber such as high temperature vulcanize silicon rubber (HTV-SiR), room temperature vulcanizing silicon rubber (RTV-SiR) and liquid silicon rubber. In this study, silicon rubber used is RTV 683, supplied by PT. Metapel.

\subsection{Coal Fly Ash (CFA)}

The characteristic of CFA mostly depends on the coal quality and combustion process. The quality of coal fly ash has been reported in [10]. Those reports show the characteristic from many sources of CFA which involves chemical content, size, microstructure and electrical resistance.

The CFA used in this research is provided by local cement industry, PT. Semen Tonasa (Persero). The Classification CFA ash used is F class according to ASTM C612.

The image of a microstructure of coal fly ash used in this study obtained from Scanning Electron Microscope (SEM) is presented in Fig. 1. It shows that the particle of CFA is irregular shape and size.

CFA is a composite material which consists of some chemical substance as presented in Table 1. The chemical contents of CFA used have been examined by using XRF (X-Ray Fluorescence).

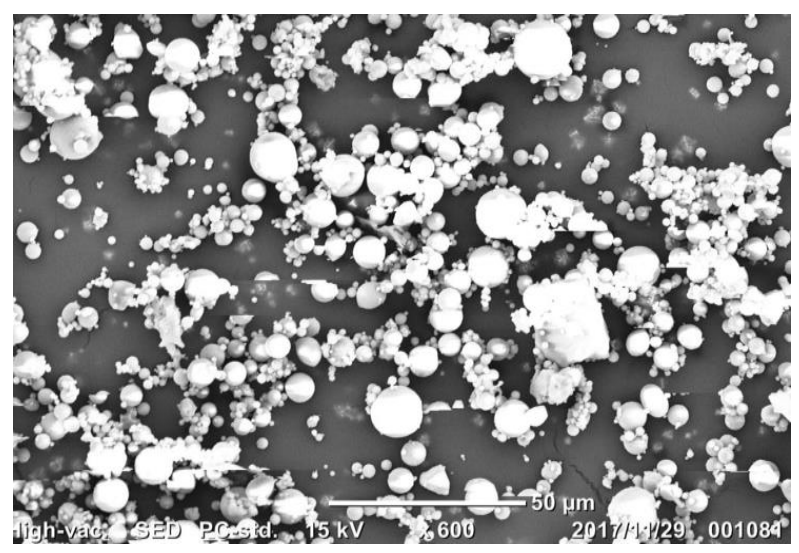

Figure 1. SEM images of coal fly ash (CFA)

Table 1. The Chemical contents of CFA

\begin{tabular}{cc}
\hline Chemical & Percentage \\
\hline $\mathrm{SiO}_{2}$ & 40.16 \\
\hline $\mathrm{Fe}_{2} \mathrm{O}_{3}$ & 20.22 \\
\hline $\mathrm{Al}_{2} \mathrm{O}_{3}$ & 19.48 \\
\hline $\mathrm{CaO}$ & 8.35 \\
\hline $\mathrm{K}_{2} \mathrm{O}$ & 1.75 \\
\hline $\mathrm{TiO}_{2}$ & 1.30 \\
\hline $\mathrm{BaO}$ & 0.19 \\
\hline $\mathrm{SrO}$ & 0.12 \\
\hline $\mathrm{ZrO}$ & 0.06 \\
\hline Others & 8.0
\end{tabular}

Table 1 highlights that vast majority contents of CFA are $\mathrm{Si}_{2} \mathrm{O}_{3}, \mathrm{Fe}_{2} \mathrm{O}_{3}$ and $\mathrm{Al}_{2} \mathrm{O}_{3}$. Those chemicals have been used as filler in composite material both on epoxy and silicon rubber in form of nano-filler or micro-filler. Their applications have proven to improve the electrical and mechanical properties of composite insulation material. Their effectiveness as a filler was determined by some factors, such as: particles size, filler loading and dispersion [3-5].

The particle size distribution of CFA has been examined by using Shimadu SALD-2300 (wing SALD II Version 3.32). Its particle size distribution is presented in Table 2 . It shows that the particle size is irregular, the vast majority of CFA particle size is equal or less than $20 \mu \mathrm{m}$.

Table 2. Range of particle size distribution of Coal Fly Ash

\begin{tabular}{cc}
\hline Range of Particle Size $(\mu \mathrm{m})$ & Percentage $(\%)$ \\
\hline $20 \geq \mathrm{x}$ & 55.14 \\
\hline $40 \geq \mathrm{x}>20$ & 29.54 \\
\hline $60 \geq \mathrm{x}>40$ & 8.47 \\
\hline $80 \geq \mathrm{x}>60$ & 3.95 \\
\hline $\mathrm{x}>80$ & 2.90
\end{tabular}


In this research different mass concentration of CFA was added as a filler into RTV Silicon rubber as a matrix. The impact of the coal fly concentration on electrical properties of silicon rubber composite would be studied.

\subsection{Sample preparation}

The silicon rubber room temperature vulcanize namely RTV 683 is applied as host matrix without any pretreatment. While coal fly ash as a filler. The silicon rubber is supplied by PT. Metapel and the coal fly ash is provided by PT. Semen Tonasa (Persero).

To investigate the effect of filler concentration on the electrical properties of silicon rubber, the samples are grouped according to the phr filler loading $0,10,20,30,40 \mathrm{phr}$ respectively. Sample with filler $0 \mathrm{phr}$ means sample without filler and investigates as references. The hardener is also applied to fasten the vulcanizing process. Material sample is vulcanized in room temperature $28{ }^{\circ} \mathrm{C}$, humidity $75 \%$.

The sample preparation consists of some steps as as presented in Fig. 2.

The material sample that consists of silicon rubber, hardener and CFA are weighed using a digital scale with accuracy up to 0.01 gram. Silicon rubber and CFA with the specific amount ratio (phr) were mixed and mechanically blended for 30 minutes at room temperature to well dispersion. The next step is vacuuming or degassing process to remove air bubble trapped (void) in the mixture. The vacuum pressure applied is $650 \mathrm{mmHg}$ for 25 minutes. Then, the mixture was molded into a circular molding pot with dimension $200 \mathrm{~mm}$ and $3 \mathrm{~mm}$ in diameter and thickness respectively. The vulcanizing time is about 2 hours at room temperature, and humidity is about $30{ }^{\circ} \mathrm{C}$ and $80 \%$ respectively. The samples were released from molding case after 3 hours. Finally, the samples put into the oven for 12 hours at $85 \mathrm{C}$ for drying. Samples produced by the above process are shown in Fig. 3.

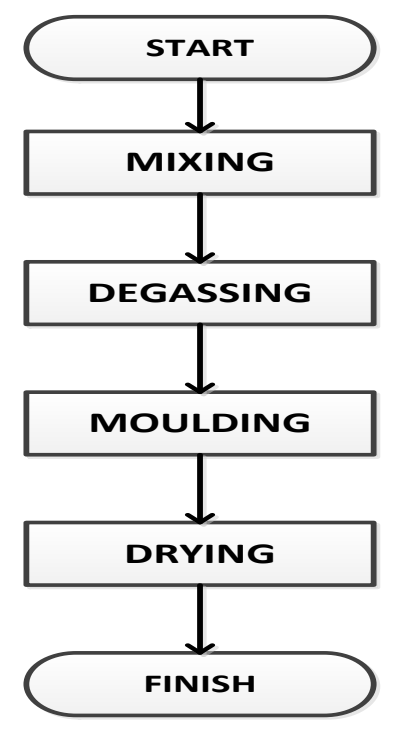

Figure 2. Sample preparation flowchart

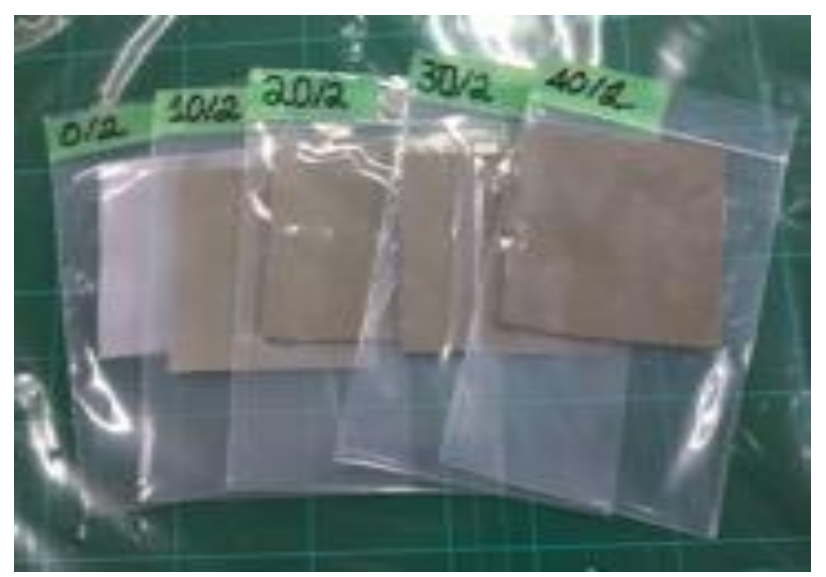

Figure 3. Sample of silicon rubber with coal fly ash filler

\subsection{Experimental method}

The electrical properties of silicon rubber with CFA filler investigated in this study consists of surface resistance, volume resistance, surface flashover and dependence of surface flashover over ambient

\subsubsection{Surface resistance}

The surface resistance of samples is measured according to ASTM standard D257. Experimental setup for surface resistance is depicted in Fig. 4.

Sample dimension was adjusted according to the size of the electrode system, $100 \mathrm{~mm}$ x $40 \mathrm{~mm} 3 \mathrm{~mm}$. The number of samples per group is 5 sample. The sample was placed on electrode system after its surface wiping with ethanol and to improve the surface contact between the electrode and the sample; the constant weight was put on the sample.

The volume conduction current of a sample was measured for 300 seconds under $1.5 \mathrm{kV}$, DC. The surface resistivity was calculated by the following equation:

$$
\rho_{s}=\frac{V \cdot W}{I_{s} \cdot d}
$$

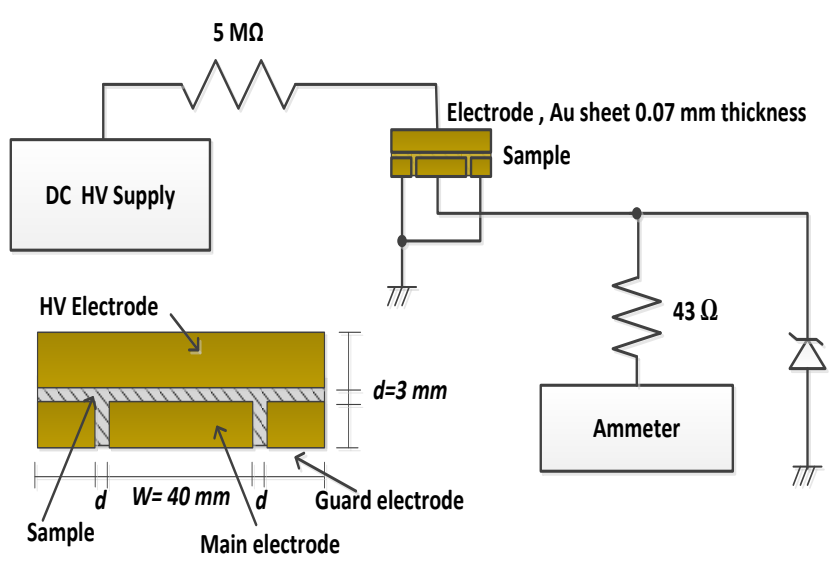

Figure 4. Surface conduction current measurement system 


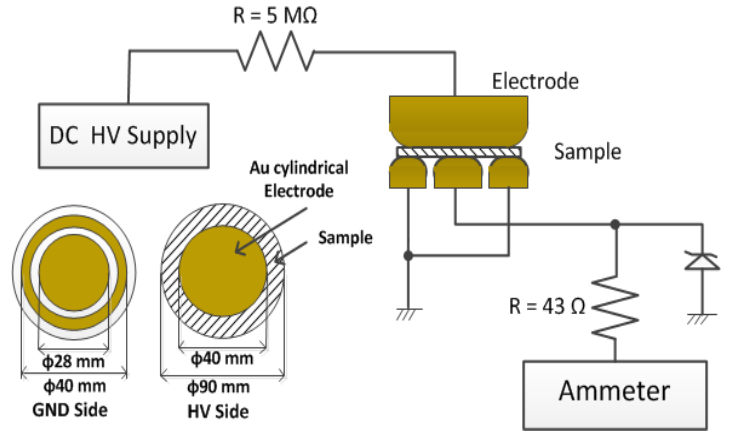

Figure 5. Volume conduction current measurement system

Where $W$ is the width of the main electrode and $d$ the distance between electrodes. $V$ is the applied voltage and $I_{s}$ is the average value of the surface conduction current after the first 60 seconds due to the transient current in this time range.

\subsubsection{Volume resistivity}

Volume resistance of samples are measured according to ASTM standard D257. Experimental set up is presented in Fig. 5. The sample was placed between HV electrode and the main electrode. To improve the contact between electrode and sample and to prevent disposition of sample, the pressure on the sample is controlled by adjusting the screw of the electrode system. HV supply is $1.5 \mathrm{kV}$, DC. Volume conduction current is measured for 300 seconds.

The volume resistivity was calculated by the following equation:

$$
\rho_{v}=\frac{V \cdot S}{I_{v} \cdot d_{v}}
$$

$S$ is the surface area of the main electrode and $d_{v}$ is the distance between $\mathrm{HV}$ electrode and main electrodes. $V$ is the applied voltage and $I_{v}$ the average value of the volume conduction current. As like on surface conduction current measurement, volume conduction current during transition time is also neglected.

\subsection{Flashover inception voltage}

Dry power frequency external flashover has been determined by averaging five flashover voltage measurements, according to IEC 60060-1. Fig. 6 shows measurement system for flashover inception voltage test.

The electrode system is a copper tape with thickness 75 $\mu \mathrm{m}$ in semicircular configuration with the diameter of 30 $\mathrm{mm}$, and the gap between electrode is $25 \mathrm{~mm}$. The sample prepared is Silicon rubber with different loading CFA filler. Sample dimension is $40 \mathrm{~mm} \times 15 \mathrm{~mm} \times 5 \mathrm{~mm}$. Before testing, samples are wiped with ethanol to eliminate contaminant on the sample surface.

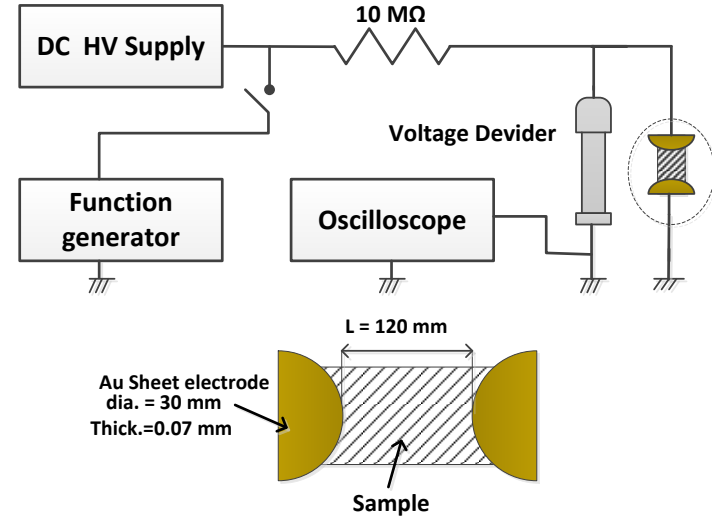

Figure 6. Flashover inception voltage experimental set up

The sample tested put into the oven. The oven temperature is adjusted to a specific temperature to simulate the ambient condition. During the test, the temperature and humidity are maintained constant. To determine the effect of temperature on FOIV of silicon rubber with CFA filler, the testing is carried at some specific temperature $25,40,60,80$ ${ }^{\circ} \mathrm{C}$ respectively. In this case, only a group sample with 30 $\mathrm{phr}$ is tested. Humidity during the testing is $58 \%$.

The FOIV has been obtained by increasing the voltage linearly to flashover with increasing rate $1.0 \mathrm{kV} / \mathrm{second}$. The DC ramp voltage is applied until the flashover on the surface of the sample occurs. The occurrence of flashover is monitored using an oscilloscope, and FOIV value is recorded.

\section{Results and Discussion}

\subsection{Volume resistivity}

The volume resistivity of silicon rubber with different CFA filler loading is presented in Fig. 7. Five valid measurement data was obtained so the accurate volume resistivity data could be calculated.

. The values presented in Fig. 7 are the average value from five measurements. It is revealed that, with the addition of CFA filler loading, the significant increase of volume resistivity is observed, but when CFA filler loading

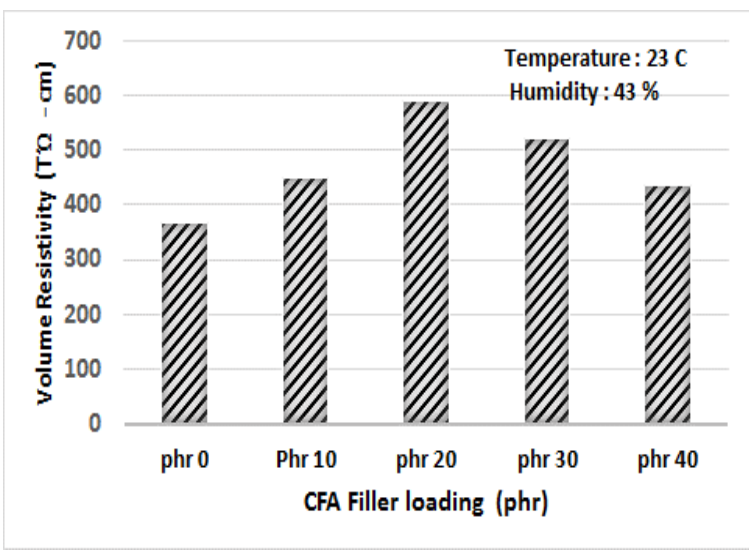

Figure 7. Volume resistivity of Silicon Rubber with different CFA filler loading 
reaches higher than $20 \mathrm{phr}$, the volume resistivity decline. The decreasing of volume resistivity after $20 \mathrm{phr}$ due to semi-conducted materials content of CFA such as $\mathrm{Fe} 2 \mathrm{O} 3$, at high filler loading internal distance between filler particles become smaller leads to the formation of resistance bridge as a consequence the volume resistance of composite tends to decrease

\subsection{Surface resistance}

Surface resistance of silicon rubber with different CFA filler loading is presented in Fig. 8. It can be seen that the surface resistance increases with increasing filler concentration. Based on the nature of electric current, when the voltage applied to the surface, current does not flow on the surface only but also inflow in the material. Therefore, the sample thickness also determined the surface resistivity. Also, the surface contaminant, temperature, and humidity affect the surface resistivity of the tested material.

The increasing of surface resistivity could be caused by some factors, such as mineral content of CFA like and are high resistance in nature. The electrical strength on the surface of the material during the testing change the property of semi-conductive mineral contained on CFA filler. The polarization of the material surface due to a high electric field may increase the surface resistivity; the longer material surface is exposed to electrical field the more surface resistivity increase.

\subsection{Flashover Inception Voltage.}

The average values of flashover inception voltage (FOIV) of silicon rubber with different CFA filler loading is presented in Fig. 9.

It can be seen from the Fig. 9, flashover inception voltage increase with the increasing of CFA filler loading. The flashover inception voltage is determined by some factors such as electrical properties, physical structure and environmental parameter on the material surface [11]. In this case, the increasing of flashover inception voltage mainly is determined by the surface resistance of silicon rubber. The higher surface resistance, the higher flashover inception voltage.

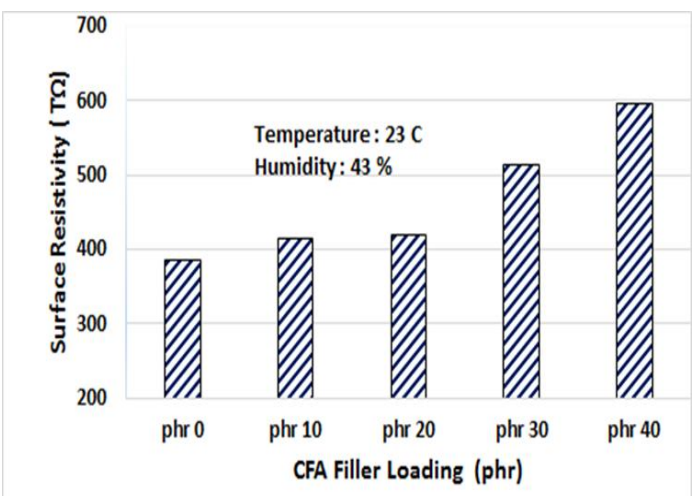

Figure 8. Surface resistivity of Silicon Rubber with different CFA filler loading.

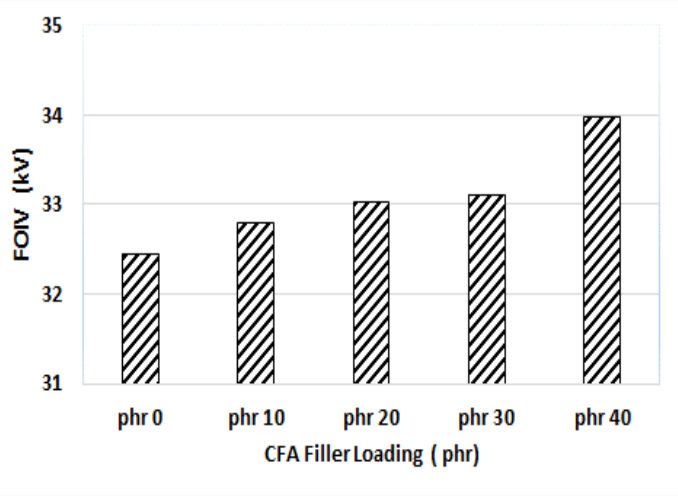

Figure 9. The effect of CFA filler loading on flashover inception voltage of Silicon Rubber

As depicted in Fig. 8, the surface resistivity increase with the increasing of CFA filler loading. Therefore, the increasing flashover inception voltage as presented in Fig. 9 directly correlated with the increase of surface resistance.

It is assumed that the surface charge is generated from the HV electrode and move toward the counter electrode [12]. The surface charge movement change by the surface resistivity of the sample. In case of high surface resistivity of the sample, the surface charge hardly moves to approach the counter electrode. Therefore, the inception voltage increase with the increase of surface resistivity of the material composite.

The effect of temperature on FOIV of silicon rubber with CFA filler is depicted in Fig. 10. It shows that as the temperature increase the VOIV also increase. Surface resistance is one of the factor affecting flashover. Since insulation resistance tends to decrease with the increasing temperature. FOIV of the silicon rubber insulation have a temperature dependence in the temperature range over 40 ${ }^{\circ} \mathrm{C}$, but it is nearly constant in the temperature range under $40{ }^{\circ} \mathrm{C}$.

In this study, the application of CFA filler on silicon rubber has shown improvement electric insulating property. Hence it has a good prospect in application in insulation material. However, further study has to be carried out for some other dielectric properties such as: hydrophobicity, permittivity, dielectric loss, and breakdown strength.

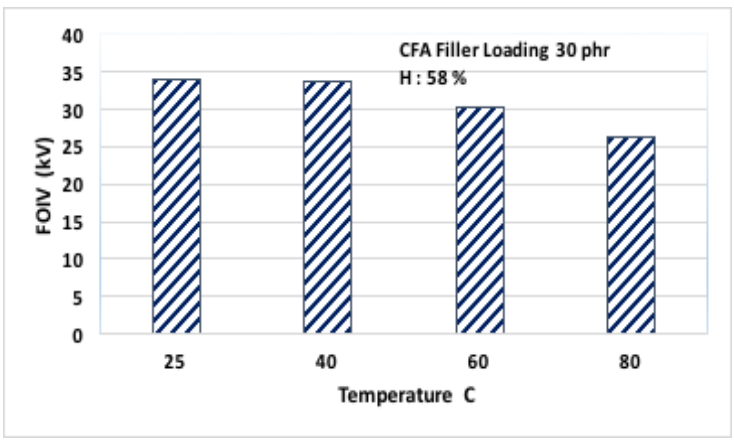

Figure 10. Dependence of FOIV of Silicon Rubber with CFA on temperature. 


\section{Conclusions}

This study, the effect of CFA as a filler on electrical properties of silicon rubber was investigated. The effects of CFA filler loading can be summarized as follow:

1) The increasing of CFA loading filler increase the volume resistivity of composite silicon rubber significantly. But when CFA filler loading reaches higher than $20 \mathrm{phr}$, the volume resistivity tens to decline.

2) The loading of CFA effectively improve the surface resistivity of Silicon rubber composite, and CFA loading filler exceed $20 \mathrm{phr}$ has a better improvement.

3) Obtained results show that flashover inception voltage increase with the increasing of CFA filler loading. In this case, the increasing of flashover inception voltage mainly is determined by the surface resistance of silicon rubber. The surface resistivity decrease with the increase of temperature yields the decline of flashover inception voltage (FOIV).

\section{Acknowledgement}

The first author would like to thanks to Project for Capacity Building in Engineering, Science and. Technology (CBEST), Hasanuddin University for doctoral scholarship at Toyohashi University of Technology.

\section{References}

[1] Kyriako Siderakis, Demosthenes Agoris, Stanslaw M. Gubanski. Salt Fog Evaluation of RTV SIR Coating WithDifferent Fillers. IEEE Transaction on Power Delivery, Vol. 23 No. 4, October 2008, pp. $2270-2277$.

[2] B.X.Du. Hydrophobicity Evaluation of Silicone Rubber Insulator
Using DC Discharge Induced Acoustic Wave. IEEE Trans. On Dielectric and Electrical Insulation, October 2013, pp.1836 - 1844.

[3] M. Ehsani, H. Borsi, E. Gockenbah, J. Morshedian, G.R. Bakhshadendeh. An investigation of dynamic, thermal, and electrical of housing materials for outdoor polymeric insulators. European Polymer Journal 40 (2004) pp. 2495-2503.

[4] Z. Li, K. Okamoto, Y. Oki and T. Tanaka. Effect of Nano Filler Addition on Partial Discaharge resistance and dielectric breakdown strength of Micro - $\mathrm{Al}_{2} \mathrm{O}_{3}$ /Epoxy Composite. IEEE Transaction Dielectr. Electr. Insulation Vol.17, pp. 653-661, 2010.

[5] Z. Li, K. Okamoto, Y. Oki and T. Tanaka. The Role of Nano and Micro Particles on on Partial Discharge and Breakdown Strength in Epoxy composite. IEEE Trans. Dielectr. Electr. Insulation, Vol. 18, pp. $678-681$

[6] I. Kitta, S. Manjang, W. Tjaronge, R. Irmawaty. Performance Study of Silicone Rubber Polymer was Filled Fly Ash as Insulator Material on High Voltage Transmission Tower, International Journal of Innovative Research in Advanced Engineering (IJIRAE), ISSN: 2349 2763, Issue 01, Volume 3, January, pp. 120-124, 2016.

[7] Shixin Zeng, Jialai Wang. Characterization of mechanical and electric properties of geopolymers synthesized using four locally available fly ashes. Elsevier Construction and Building Material 121 (2016) pp. $386-399$.

[8] Shin-Etsu. Characteristic Properties of Silicone Rubber Compounds. http://www.silicone.jp/e/catalog/pdf/rubber_e.pdf.

[9] Anjum Saleem, Lars Frormamn, Alexander Soever. Fabrication of Entrinsically Conductive Silicon Rubbers with High Elasticity and Analysis of Their Mechanical and Electrical Characteristics. Polymer 2010, ISSN 2073-4360.

[10] Avinash Candra. Some Investigation on Fly Ash Resistivity Generated in India Power Plants. 11th International Conference on Electrostatic Precipitation, 2010.

[11] S. Venkataraman, R. S. Gorur and A. P. Mishra. Impact of Weathering on Flashover Performance of Nonceramic Insulators. IEEE Transactions on Dielectrics and Electrical Insulation, Vol. 15, No. 4, August 2008, pp. 1073-1080.

[12] H. Tanaka, T. Kawashima, Y. Murakami, M. Nagao. Flashover Characteristics of Silicon Rubber Surface Influenced by Surface Charge. Annual Report Conference on Electrical Insulation and Dielectric Phenomena, 2015. 